\title{
Online Grocery Shopping: Identifying Change in Consumption Practices
}

\author{
Jo Munson, Thanassis Tiropanis, and Michelle Lowe \\ Web Science Institute, University of Southampton, UK \\ \{J.Munson, T.Tiropanis, M.Lowe\}@soton.ac.uk
}

\begin{abstract}
Following the invention and proliferation of the Internet, Web and mobile technologies, we have seen a global revolution in retailing. Despite the rapid growth of e-commerce, the online grocery shopping market has taken until now to gain traction, currently constituting $6.9 \%$ of the UK's grocery market, but projected to increase $68.3 \%$ to $£ 17.6$ bn by 2021 . There is little work accounting for new and contingent behaviours in the online grocery market, not least because of historically poor access to retailers' data. This paper leverages access to the UK's fourth largest supermarket, WM Morrisons Plc (Morrisons) to investigate consumer behaviour in this market, augmenting the Office for National Statistics' Living Costs and Food Survey, the UK's only substantial publicly available resource to date. This paper establishes that there have been changes in consumer behaviours in response to the unique opportunities and challenges of online grocery shopping and explores the specific socio-technical factors that may be contributing to these changes, namely: ease of price comparison; attitudes to purchasing perishable goods online; and logistical considerations. Furthermore, it provides some evidence that the proportion of fresh products bought online exceeds the proportion bought offline, contrary to popular belief. Finally, this paper argues that with correction for location bias, the Morrisons sample could provide a proxy for examining online grocery behaviour in-depth at the national level.
\end{abstract}

Keywords: Online Grocery Shopping, E-commerce, Consumer Behaviour, Retail Analytics, Socio-technical Systems

\section{Introduction}

Following the invention and proliferation of the Internet, Web and mobile technologies, we have seen a global revolution in retailing. Online retail sales are surpassing expectations in the UK, exceeding £133bn in 2016, a $16 \%$ increase on 2015 2. As at March 2017, the Office for National Statistics (ONS) report that $15.0 \%$ [10] of all retail spending now occurs online (up from $8.5 \%$ in 2012 [29].) Despite this surge in online shopping, one sector that has been slow to embrace the e-tail revolution is grocery shopping. The slower growth in this sector has been attributed to two factors: supply-side issues (such as low margins and the logistical constraints of low-density deliveries [17, 26]); and conservative 
demand. Low demand is often attributed primarily to consumers' desire to pick their own perishable goods such as fresh fruit, vegetables and meat [19, 38. Despite significantly slower market penetration, the UK is one of the few countries that has established a growing online grocery market, currently worth c.£10.5bn p.a. [16. Online food shopping in Great Britain currently constitutes $6.9 \%$ of the UK's grocery market 43 and IGD predict the value of the UK's online grocery market will increase $68.3 \%$ to $£ 17.6$ bn by 2021 [16]. Tesco claim to have made profits of $£ 127 \mathrm{~m}$ from online grocery sales in 2013 [27], whilst Pure-play retailer Ocado posted profits of $£ 14.5 \mathrm{~m}$ over 2016 [5].

With growth now well established in the UK's online grocery market, it is a poignant time to investigate whether their have been changes in grocery consumption behaviour in the new online context. As in other e-tail sectors, a number of market analysts have argued that there is a huge opportunity in online grocery shopping to gain insight into consumer behaviour via "Big Data" accumulated by online consumption [22, 28]. Despite this, there is little work accounting for new and contingent behaviours, not least because of historically poor access to retailers' data. Understanding behavioural change entails gamechanging potential for retailers, particularly in a low-margin industry such as the UK grocery market. The opportunities afforded by increased insight are numerous with respect to customer retention, complementary service provision, online and physical store planning, better lifetime value prediction, personalisation and brand reputation. The usefulness of understanding online grocery consumption is not limited to retailers however. Governments and town planners can benefit from understanding movement flows and practices in order to plan services more effectively. Technology designers can benefit from understanding technology use, especially in the interpretive flexibility of technologies. From an academic perspective, insights into consumer movements, habits and shopping practices contribute to the broader thesis of understanding socio-technical systems, social change and consumption behaviour.

To date, the most comprehensive publicly available data covering online grocery shopping in the UK is published by ONS in their annual Living Costs and Food Survey (LCF), the latest of which separates online grocery shopping from supermarket and other food outlet shopping [4]. Whilst the LCF provides a valuable starting point for uncovering changes in grocery consumption behaviour, its scope is limited to spending by food category for a sample of c.4,000 households. The LCF does not collect and collate information about use of mobile devices, how users interact with online stores or where and when they do their grocery shopping. The authors of this paper have been granted access to a large and high quality dataset of real online grocery transactions via the Google Analytics account of WM Morrisons Plc (Morrisons). Google Analytics allows analysis of consumer activities at the level of the individual and facilitates analysis of the place, device, timing and browsing behaviour of customers.

Morrisons does not currently deliver nationally and the customer base is significantly overrepresented in the North West and Yorkshire and the Humber regions relative to the general population. As a corrective to the potential bias in 
the sample we re-weight findings using population averages and show that there is significant potential to use the Morrisons sample to explore online grocery consumption at the national level. This paper establishes that that there have been changes in consumer behaviours in response to the unique opportunities and challenges of online grocery shopping and explores the specific socio-technical factors that may be contributing to these changes.

\subsection{Aims of the Study}

This paper provides an initial assessment of the potential to use the Morrisons dataset for exploring national level online grocery behaviour and examines in detail the features of online grocery that are thought to constrain or change behaviour - customer reticence buying perishable and tangible food stuffs; the ability to compare prices with Web search; and the perceived tendency for consumers to revert to "favourites" or previous orders. Specifically, this paper addresses the following questions:

- Is the Morrisons sample representative of online grocery shopping at the National Level?

- Are there differences in consumption behaviour between online and offline grocery shopping in the UK?

- Are online grocery shoppers price sensitive?

- Are online grocery baskets stable?

The next section of this paper gives a brief overview of relevant grocery and e-commerce research and identifies gaps in the literature motivating this work.

\section{Background}

\subsection{Online Grocery Shopping - Adoption, Retention and Motivation}

Attracting and retaining customers has always been of primary concern to retailers and with some estimating that a $5 \%$ increase in customer retention can lead to profit increases of nearly $100 \%$, it is easy to see why 33. Rafiq et al 32 . found that offline interaction with the brand and "word of mouth" recommendation online were the most important predictors of choosing and continuing to use the services of an online retailer. Rafiq et al [32] also found that market leader Tesco's success in gaining customers from other retailers was an exemplification of the 'double jeopardy effect', i.e. that those with lower market share also suffered lower brand loyalty. This effect was also shown to be true for individual products in Danaher et al's study of grocery shoppers in New Zealand 8.

HCI, psychology and market research analysis of online consumption has centred largely on brand-impervious motivations for technology adoption. Hansen [14] postulates that OGS is a 'discontinuous innovation' requiring a significant shift in behaviour and thus a more drawn-out adoption period. Hand et al found that being adept internet users was not sufficient to assume a propensity to 
engage with online shopping and that when online shopping was adopted, it did not usually entail the discontinuation of offline shopping [13. Several studies have employed various incarnations of the Technology Acceptance Model (TAM). In one such study, Evanschitzky et al 12 recognised the importance of context in the adoption of technologies. They identified the 'human-to-human' consumer-retailer interaction as having been replaced with 'human-to-computer' interaction as a key differentiator between offline and online customer satisfaction. They reported a moderately good fit with Szymanski and Heise's results concluding that some drivers of E-satisfaction may be context invariant [12, 37]. TAM studies tend to be deployed in experimental settings and often involve the "simulation" or "intention" to adopt a technology or behaviour, but do not assess the uptake or continued use of the technology. This is justified on the assumption of an 'Intention-Behaviour' link, i.e. the assumption that a customer's reported intentions are played out in their subsequent actions. Bagozzi describes the link as 'probably the most uncritically accepted assumption in social science research' 11. Bagozzi goes on to criticise TAM for its simplistic model of human action, which fails to recognise that engagement with a given technology or service is rarely a"terminal goal" in itself for the consumer. Instead, he suggests that intentions and goals are continuously negotiated as users look to overcome obstacles, resist temptations and maintain willpower to achieve evolving goals [1].

Whilst these studies provide a good exploratory starting point for understanding consumption behaviour, they have rarely been verified or explored in combination with real-world online transaction data. This study uses an extensive corpus of real-world data to assess whether there are differences in consumption behaviour between online and offline grocery shopping in the UK.

\subsection{Mobile Technologies and Online Grocery Shopping}

As we move into an era where technological interfaces form the basis of many of our social and commercial activities, consumer behaviour has acquired a further layer of complexity [18. Increased reliance on the Web presents potentially transformative effects in terms of our individual relationships with food, shopping and roles within the household; but also raises questions about the design and effects of the interfaces themselves. Mobile technologies not only pervade our homes, but also move with us, facilitating a relocation of (grocery) consumption from the physical store to "potentially anywhere". Crewe and Lowe [7] discussed spatial heterogeneity in terms of 'micro-geographies of consumption' [7] where they argued that retailers create highly individual consumption spaces, quite apart from the perceived globalisation effect 34. The implications of consumption that happens "anywhere" entails that consumption depends not only on the virtual space that is the Web interface, but also on the diverse array of physical spaces in which the consumption takes place. In focus group discussions with online shoppers, Michaud Trevinal and Stenger [23] found that many respondents enjoyed the affordances of being in a familiar, relaxing environment with the capacity to move between tasks, or research items on different websites when 
shopping online. The appeal of this ability to "multi-task" was echoed by respondents in Robinson et al's study [35. Robinson et al [35. conducted focus groups with 32 online grocery shoppers and found that respondents rarely purported to having a regular time or place for shopping, 'sometimes from home, sometimes from work, other times in the middle of the night.' 35.

Maity and Dass [20] found that the channel of consumption affected decision making and propensity to buy. Respondents preferred shopping in-store to on mobile devices, which the authors attributed to mobile phones' low 'media richness'. The convenience of e-commerce (via a desktop/laptop device) surpassed its relatively lower media richness compared to in-store, rendering it the most popular channel. Wang et al's study of M-shopping indicated a tendency to opt for branded or "known" products due to the constraints of the small screen size making it harder to research and evaluate new items [42. Briesch et al's [3] offline study of 11,005 store visits indicated that retailers with more brands increased their probability of a household choosing their store, but that those with fewer SKUs per brand also attracted greater loyalty. Wang et al's 2015 study of c 16,000 consumer activities on a US-based online grocery platform represents the most comprehensive study to date [42]. The study used real-world data to examine the effect of mobile use on consumption behaviour. They found that consumers using mobile devices for online grocery shopping, 'M-shopping', increase in value over time, ordering more frequently as they become accustomed to the technology and interface. They also suggested that engagement with Mshopping resulted in low income consumers spending more than they did prior to commencing M-shopping. We are not aware of any study of this scale looking at UK audiences.

With notable exceptions [3, 42] most online grocery shopping research to date has been qualitative in nature or based on self-reporting of behaviour and preferences in small-scale studies. This study redresses this balance by considering the real-world behaviours of hundreds of thousands of consumers and looks specifically to identify whether there are changes in consumption activities in the new online context. Future work will also look at identifying and verifying changes in consumption in the wake of the mobile technologies.

\subsection{Trust, Price Sensitivity and Thrift}

Another common theme emanating from previous studies is the lack of trust associated with purchasing fresh produce online. It has been found that consumers are worried about substitutions, the shelf-life of perishable goods and sub-optimal selection of fresh produce [13]. As a result, it has been reported that many online grocery shoppers continue to visit physical stores to purchase fresh food items [13]. However, this finding is not universal. Contrary to retailer's fears that price comparability online would spark intensified price competition, Degeratu et al found that online consumers may not be as price sensitive as the general population. They also reported that brand loyalty was more likely to persist online where there was a paucity of information [9]. This could have 
implications for all food stuffs, but particularly "fresh", where customers usually rely on sensory perception to evaluate items. This may imply a tendency to opt for branded, pre-packaged fresh goods. This study will add to this debate by comparing online and offline consumption of perishable and nonperishable goods.

Grocery shopping literature has long focussed on consumers' ability exhibit good economic sense, or "thrift". In his 1998 book, Miller claimed, "That which the shopper does on behalf of the household is governed by thrift, while their individual presence is signified by the treat.' [24]. If this observation has merit, then one might suppose that the asocial nature of shopping on a personal device might lead to a higher propensity to "treat" oneself. Anecdotal evidence [11] suggests that this is not the case - that in fact online grocery shopping is used as a tool for planned, thrifty shopping and that it is the physical convenience stores that are frequented to top up on the treats that one tried to abstain from in the weekly shop. Robinson et al [35] also alluded to a potential shift in shopping consumption behaviour associated with showing thrift in the online context. They found that users place orders less regularly to justify the cost of delivery charges, but that baskets may also be correspondingly bigger, as to diminish the marginal cost of delivery. Despite this, Huang and Oppowal found that physical distance from the supermarket was a more important predictor of tendency to shop online than delivery charges [15]. This was consistent with the findings of Briesch et al [3], who found distance to travel has a larger effect on retailer selection than price or product assortment. In the online context however, where distance is removed as a variable among online retailers, price and product variety may play a larger role in choice of retailer.

This study contribute to this discussion in addressing the question, 'Are Online Grocery Shoppers Price Sensitive?'. This will be achieved by looking for evidence of thrifty behaviours and by comparing the average size of online baskets with offline national averages.

\subsection{Time Poverty and Basket Stability}

Twenty-first century families, particularly "working mothers" are often referred to as 'time poor' Wajcman [41] and time is often cited as the primary reason for online shopping. However, time poverty has not been universally reported in studies to date. Whilst Robinson et al [35] found that regular shoppers had reduced their shop time to minutes, facilitated by features such as "favourites", Michaud Trevinal and Stenger [23] described how users' propensity to multitask meant that online shopping was done over an extended period. Furthermore, Huang and Oppowal found no evidence to support time being a factor of convenience for online over physical shopping [15]. Rohm and Swaminathan's [36] online shopper typology cites four distinct user types and may help account for disparity in findings regarding time ad price sensitivity. Rohm and Swaminathan's "convenience" motivated group were the most likely to engage in online shopping [36]. Their characteristic attributes included lower requirement for variety (across retailers) and lower sensitivity to receiving products immediately 
than the supermarket shopping population at large. The use of "favourites" and site search will be scrutinised in this study, when looking to establish whether online grocery baskets are quick to stabilise.

This section has summarised literature in the field of online grocery shopping and has identified gaps in the literature, namely a paucity of empirical real-world quantitative analysis of online grocery shopping; and little empirical evidence of user's response to the new online context in terms of price sensitivity, total spend and product selection. In this paper, we focus on establishing whether there is evidence of differences between online and offline grocery consumption. We also examine whether online grocery shoppers are price sensitive and difficult to sell new products to.

\section{Methodology}

This study employed an exploratory approach using Morrisons' online transaction data and comparing it with online and offline national average estimates, as produced by the Office for National Statistics (ONS) in the Living Costs and Food Survey 2016 (LCF 2016) 4]. In so doing, this study examined the extent to which the Morrisons sample can be used to investigate online grocery shopping at the national level.

To establish whether the composition of Morrisons' online baskets was comparable with national estimates for online and offline baskets, an analysis of basket composition by food category was conducted, as outlined in 3.1, 'Product Categories and Freshness'. This included re-weighting of the Morrisons sample to reflect the increased proportion of Morrisons customers located in the North West and Yorkshire and the Humber regions.

To establish how Morrisons users populate their online grocery baskets (with respect to basket stability, price savviness and product discovery), an analysis of the page from which products were added to basket was performed, as outlined in 3.1, 'Basket Stability and Price Sensitivity'.

\subsection{Sample Preparation and Processing}

Table 1. Morrisons sample composed in line with the technique used by LCF 2016

\begin{tabular}{ll}
\hline Day of Week & Selected Date \\
\hline Monday & $23 / 11 / 2015$ \\
Tuesday & $28 / 04 / 2015$ \\
Wednesday & $11 / 11 / 2015$ \\
Thursday & $02 / 07 / 2015$ \\
Friday & $30 / 10 / 2015$ \\
Saturday & $29 / 08 / 2015$ \\
Saturday & $07 / 02 / 2016$ \\
\hline
\end{tabular}


Product Categories and Freshness The Morrisons Sample consisted of 986,973 transacted food and drink items from 41,000 users/households obtained using the Google Query Explorer API. The sample was selected to broadly mimic the methodology used by the ONS [4] by partitioning dates into weeks and then taking randomly selected dates corresponding to each of the days of the week to form a sample "week" for comparison with the Living Costs and Food Survey April 2015 to March 2016 (LCF 2016) (Table 1).

Table 2. Composite food categories derived from COICOP codes

\begin{tabular}{|c|c|}
\hline Category Label & Products Included \\
\hline Bread \& Cereals & $\begin{array}{l}\text { Bread, pasta, lentils, pulses, savoury biscuits and buns, } \\
\text { breakfast cereals, corn-based products, quiches, } \\
\text { pastries, non-meat pies }\end{array}$ \\
\hline Fruit \& Veg & $\begin{array}{l}\text { Fresh, dried, frozen and processed fruit and veg, } \\
\text { including potatoes }\end{array}$ \\
\hline Meat & $\begin{array}{l}\text { Fresh, cured and frozen meat products } \\
\text { including meat pies }\end{array}$ \\
\hline Fish & $\begin{array}{l}\text { Fresh, processed and frozen fish } \\
\text { including battered fish }\end{array}$ \\
\hline Dairy \& Eggs & $\begin{array}{l}\text { Fresh and dried milk, cream, yoghurts, eggs } \\
\text { and dairy substitutes }\end{array}$ \\
\hline Confectionary & $\begin{array}{l}\text { Biscuits, cakes, sweet buns, sweets, chocolate, ice-cream, } \\
\text { jelly, sugar, jams and sugared spreads }\end{array}$ \\
\hline Non-Alc. Drinks & $\begin{array}{l}\text { Beverages not containing alcohol, } \\
\text { including tea and coffee }\end{array}$ \\
\hline Other & $\begin{array}{l}\text { Including soup, seasoning, baby food, butter, } \\
\text { vegetable oils and protein food replacements }\end{array}$ \\
\hline
\end{tabular}

The LCF 2016 "population proxy" collected by the ONS consisted of 4,760 households who were asked to document their spending on food over a two week period. The aggregated results were then reported as spend in £p.w. and divided by product category, broadly inline with the Classification of Individual Consumption According to Purpose (COICOP) codes [39]. The socio-demographic profiles of respondents were collected to map the results of this sample back to the parent population. The LCF forms the most complete estimate of national spending on food and drink, despite the relatively small sample size. For our study, a subsample of the COICOP codes was used to group foods into larger categories, to reduce the number of poorly categorised foods (e.g. ready meals containing a number of ingredients). The selected categories corresponding to major food groups are detailed in Table 2 .

31,721 Morrisons products corresponding to those transacted by consumers in the sample time period were labelled with one of the categories in Table 2 and were also labelled "fresh" or "not fresh". The revenue (£p.w.) was then calculated 
Table 3. Proportion of Morrisons' customers by location compared to 2015 mid-year population estimates 25,31 .

\begin{tabular}{llll}
\hline Region & Morrisons Sample & Mid-year 2015 & Diff \\
\hline West Midlands & $13.9 \%$ & $8.7 \%$ & $+5.2 \%$ \\
South East & $4.7 \%$ & $15.3 \%$ & $-10.6 \%$ \\
North West & $13.9 \%$ & $10.9 \%$ & $+3.0 \%$ \\
East & $3.0 \%$ & $10.2 \%$ & $-7.2 \%$ \\
Yorkshire and The Humber & $21.5 \%$ & $7.8 \%$ & $+13.7 \%$ \\
South West & $5.7 \%$ & $9.2 \%$ & $-3.5 \%$ \\
East Midlands & $11.3 \%$ & $7.5 \%$ & $+3.8 \%$ \\
London & $25.4 \%$ & $13.4 \%$ & $+12.0 \%$ \\
North East & $0.3 \%$ & $3.6 \%$ & $-3.3 \%$ \\
Scotland & $0.1 \%$ & $8.8 \%$ & $-8.7 \%$ \\
Wales & $0.2 \%$ & $4.6 \%$ & $-4.4 \%$ \\
\hline
\end{tabular}

Table 4. Factors characterising price sensitive, stable and disrupted adds to basket

\begin{tabular}{lll}
\hline Price Sensitive & Stable & Disrupted \\
\hline Offers & Shopping list & $\neg$ Shopping list \\
Flash sales & Favourites & $\neg$ Favourites \\
Sort by price ascending & Suggested order & $\neg$ Suggested order \\
& Previous order & $\neg$ Previous order \\
\hline
\end{tabular}

for each product category. Table 3 shows that there is a clear discrepancy between the distribution of Morrisons customers and the national averages. Re-weighting of the sample was thus performed using the ONS mid-year population estimates [31 to re-calibrate the Morrisons sample. Due to the categorical non-ordinal nature of the data, comparison with the online and offline LCF 2016 spending data was done using 1-sample $\chi^{2}$ tests.

Basket Stability and Price Sensitivity A random sample of 195 million products transacted by Morrisons customers between 1 February 2016 and 1 February 2017 was obtained using the Google Query API from Morrisons' Google Analytics account. The "ga:productListName", "ga:pagePath" and "ga:eventLabel" dimensions were used to characterise products in terms of basket stability and price sensitivity. A summary of the factors used to characterise each group are shown in Table 4. Aggregated revenue was used to calculate average basket compositions by stability and price sensitivity. 


\section{Results}

\subsection{Average Basket Value}

The average basket value for the Morrisons sample per household per week (p.h.p.w.) was $£ 33.56$, considerably higher than the $£ 20.93$, as reported by the LCF 20161

\subsection{Product Categories and Freshness}

Online LCF 2016 vs. Offline LCF 2016 The latest release of the LCF separated online grocery shopping by food category from offline spending. In order to assess whether there is a statistically significant difference in the distribution of products bought online and offline, we perform a 1-sample $\chi^{2}$ test. The null hypothesis is defined as $H_{0}^{1}$ below.

Null Hypothesis $\mathbf{1}\left(\boldsymbol{H}_{\mathbf{0}}^{\mathbf{1}}\right)$ The distribution of revenue between food categories for the LCF online survey 2016 is drawn from the same population as for the LCF offline survey 2016.

Table 5. LCF online vs. LCF offline - distribution of revenue by food category

\begin{tabular}{ll}
\hline $\mathrm{df}$ & 7 \\
$\alpha$ & 0.005 \\
$\chi_{0.005,7}^{2}$ & 20.278 \\
$\chi^{2}$ & $82.592 \gg \chi_{0.005,7}^{2}$ \\
$\phi$ & 0.09 \\
Result & Strong evidence to reject $H_{0}^{1}$ \\
\hline
\end{tabular}

The results of the 1 -sample $\chi^{2}$ test comparing the distribution of revenue by food category in $£ 0,000$ s indicate strong evidence to reject $H_{0}^{1}$ with $\chi^{2}=$ $82.592 \gg \chi_{0.005,7}^{2}=20.278$. Due to the the large sample sizes (revenues in the $£ \mathrm{~m}), \chi^{2}$ test results can be misleading. For example, a $£ 5$ variation in revenue between food categories would seem significant compared with a total revenue of $£ 50$, but significantly less if the total revenue was $£ 5 \mathrm{~m}$. The samples have been scaled to help account for this, but we also present the sample-size ambivalent measure of "effect size", given by:

$$
\phi=\sqrt{\frac{\chi^{2}}{n}}
$$

where $\mathrm{n}=$ total number of observations (total revenue) and standardised residuals given by:

${ }^{1}$ Calculated by dividing the total revenue for online grocery shopping by the number of households reported to have done grocery shopping in the last 12 months 


$$
\text { standardised residuals }=\frac{(\text { observed }- \text { expected })}{\sqrt{\text { expected }}}
$$

Cohen suggests that $\phi=0.1$ indicates a small effect size, $\phi=0.3$ a moderate effect size and $\phi=0.5$ a large effect size 6]. As such, we see that despite the large $\chi^{2}$, there is still only moderate evidence that the online LCF sample is significantly different from the offline LCF sample.

Examination of the standardised residuals reveals that the major contributors to the difference between the samples is the proportions of revenue from "Meat" (which is overweight in the online sample) and the "Other" category. Only the adjusted residual for "Other" category is statistically significant with a residual of $-8.6<-1.96$ (97.5 percentile Z-score).

Table 6. Morrisons sample vs. LCF online 2016 - distribution of revenue by food category

\begin{tabular}{ll}
\hline $\mathrm{df}$ & 7 \\
$\alpha$ & 0.005 \\
$\chi_{0.005,7}^{2}$ & 20.278 \\
$\chi^{2}$ & $20.659>\chi_{0.005,7}^{2}$ \\
$\phi$ & 0.14 \\
Result & Evidence to reject $H_{0}^{2}$ \\
\hline
\end{tabular}

Online LCF 2016 vs. Morrisons Online Sample To assess whether the Morrisons online sample is representative of online grocery consumption at the national level, we perform a 1-sample $\chi^{2}$ test with null hypothesis:

Null Hypothesis $2\left(\boldsymbol{H}_{\mathbf{0}}^{2}\right)$ The distribution of revenue between food categories for the Morrisons group is the same as the LCF online survey 2016 (representing the national average)

The results of the 1 -sample $\chi^{2}$ test (Table 7 ) comparing the distribution of revenue by food category in $£^{\prime} 00 \AA^{2}$ indicate some evidence to reject $H_{0}^{2}$. The effect size given by $\phi=0.14$ indicates slightly more disparity between the two online samples than between the online and offline LCF S samples. Examination of the standardised residuals reveals that the major contributors to the difference between the samples is the proportions of revenue from "Bread and Cereals" (which is overweight in the Morrisons sample) and statistically significant with a residual of $4.0>1.96$ (97.5 percentile Z-score).

\footnotetext{
${ }^{2} £^{\prime} 00$ s was chosen since an increase in 1 frequency point corresponds to a reasonable c. $2 \%$ swing in value for the category with least revenue, "Fish \& Seafood"
} 
Table 7. Morrisons sample (weighted by region) vs. LCF online 2016 - distribution of revenue by food category

\begin{tabular}{ll}
\hline df & 7 \\
$\alpha$ & 0.005 \\
$\chi_{0.005,7}^{2}$ & 20.278 \\
$\chi^{2}$ & $19.195<\chi_{0.005,7}^{2}$ \\
$\phi$ & 0.14 \\
Result & Insufficient evidence to reject $H_{0}^{3}$ \\
\hline
\end{tabular}

Online LCF 2016 vs. Morrisons Online Sample (Re-weighted) As shown in Table 3, Section 3.1, there is significant evidence of bias in the location of the shoppers in the Morrisons sample. The next section considers the effect of reweighting the sample by region. We therefore propose re-weighting by region, where the weighting factors are given by:

National expected proportion for region Morrisons observed proportion for region

We then assess how effective this re-weighting of the sample by region is by proposing the hypothesis:

Null Hypothesis $3\left(\boldsymbol{H}_{\mathbf{0}}^{\mathbf{3}}\right)$ The distribution of revenue between food categories is the same for the Region Re-Weighted Morrisons sample and LCF online survey 2016

Finally, noting that the ONS data detailing spend on groceries by region does not separate online and offline expenditure, we propose a further re-weighting using data for the proportion of the population of each region who have used the internet in the past 3 months (as at 2016) [30].

Null Hypothesis $4\left(\boldsymbol{H}_{\mathbf{0}}^{4}\right)$ The distribution of revenue between food categories is the same for the region re-Weighted, Internet users by region re-weighted Morrisons sample and LCF online survey 2016

Table 8. Morrisons sample (weighted by region and regional Internet use) vs. LCF online 2016 - distribution of revenue by Food category

\begin{tabular}{ll}
\hline df & 7 \\
$\alpha$ & 0.005 \\
$\chi_{0.005,7}^{2}$ & 20.278 \\
$\chi^{2}$ & $19.093<\chi_{0.005,7}^{2}$ \\
$\phi$ & 0.13 \\
Result & Insufficient evidence to reject $H_{0}^{3}$ \\
\hline
\end{tabular}


The results of the $\chi^{2}$ test shown in Table 8 indicating that with re-weighting by region and internet use by region, the Morrisons sample is not significantly different from the Online LCF 2016 survey sample. There is however relatively little improvement over the re-weighting by region only. In summary, the unweighted, re-weighted by region and re-weighted by region and internet use by region are shown in Table 9 .

Table 9. Summary of $\chi^{2}$ and $\phi$ (effect size) for unweighted and re-weighted Morrisons sample compared to LCF online survey 2016

\begin{tabular}{lll}
\hline & Effect size $(\phi)$ & $\chi^{2}$ result \\
\hline Unweighted & 0.1357 & Reject $\mathrm{H}_{0}$ \\
Weighted by Region & 0.1292 & Fail to Reject $\mathrm{H}_{0}$ \\
Weighted by Region \& Internet Use & 0.1288 & Fail to Reject $\mathrm{H}_{0}$ \\
\hline
\end{tabular}

Freshness It is often reported that online grocery shopping is unsuitable for purchasing fresh produce due to the delay in delivering goods to the consumer and the fact customers cannot pick their own perishable products [19, 21]. We test this assertion for our weighted sample against the LCF offline survey 2016.

Null Hypothesis $\mathbf{5}\left(\boldsymbol{H}_{\mathbf{0}}^{\mathbf{5}}\right)$ The distribution of revenue between fresh and nonfresh produce is the same for the re-weighted Morrisons online sample and the LCF offline survey 2016 (augmented with FFS 2015)

Table 10. Morrisons (weighted by region and regional Internet Use) vs. LCF offline distribution of revenue by freshness

\begin{tabular}{ll}
\hline df & 1 \\
$\alpha$ & 0.005 \\
$\chi_{0.005,7}^{2}$ & 7.879 \\
$\chi^{2}$ & $9.542<\chi_{0.005,7}^{2}$ \\
$\phi$ & 0.09 \\
Result & Sufficient evidence to reject $H_{0}^{5}$ \\
\hline
\end{tabular}

Table 10 shows that there is sufficient evidence to reject $H_{0}^{5}$ at the $0.5 \%$ level, although this is accompanied by a small effect size, $\phi=0.09$. Inspection of the distribution between fresh and non-fresh indicates that the proportion of fresh products is larger in the Morrisons weighted sample than in the LCF offline sample suggesting that there may in fact be a higher proportion of fresh products sold online. 


\subsection{Basket Stability and Price Sensitivity}

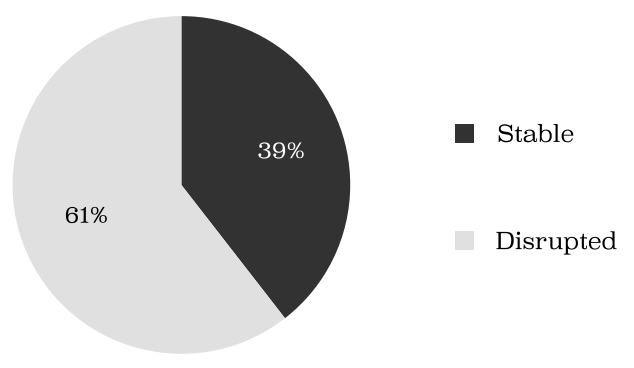

Fig. 1. Basket composition

Fig. 1 shows the breakdown of the average basket over 2016 in terms of "basket stability". The "stable" portion, constituting $39 \%$ of the average basket corresponds to products added to basket from user-specified "favourites", saved "shopping lists" and "previous orders".

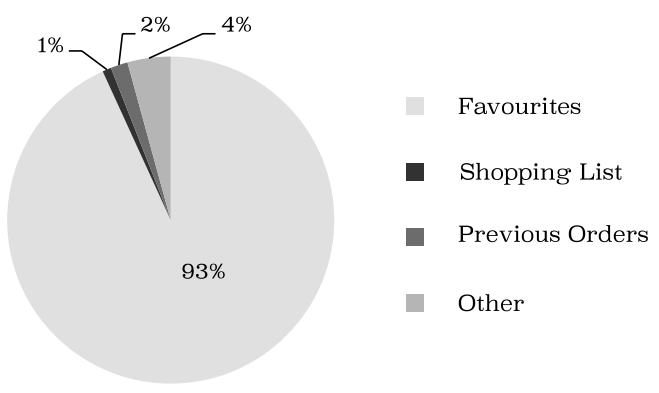

Fig. 2. Breakdown of stable product adds

Fig. 2 shows that product adds from "favourites" were by far the most significant stabilising component, accounting for $93 \%$ of the $39 \%$ stable basket. 


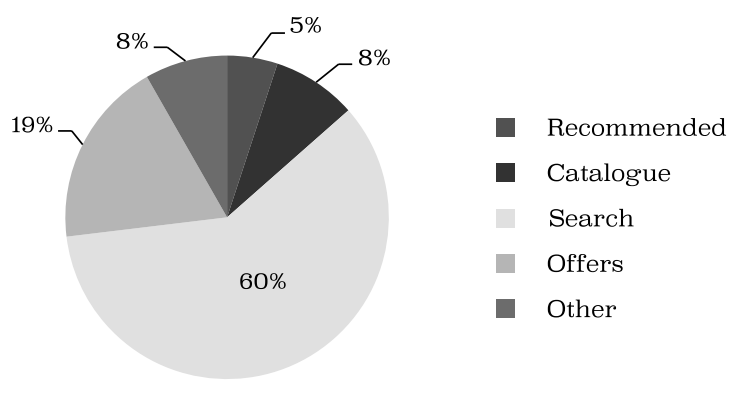

Fig. 3. Breakdown of disrupted product adds

Fig. 3 shows that the majority of product adds are considered "disrupted" since they required engagement with offers, featured/recommendations or site navigation to find relevant products.

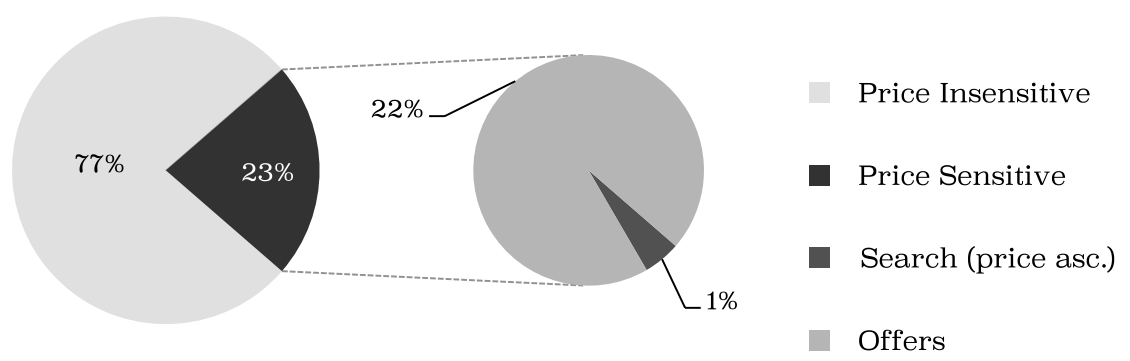

Fig. 4. Breakdown of price sensitive product adds

Fig. 3 shows that $60 \%$ of the disruptive product adds came from engagement with the site search, with only $8 \%$ adds originating from the hierarchical site navigation. Engagement with offers yielded the second largest proportion of the disruptive product adds at $19 \%$.

"Price savvy" behaviours were defined as those emanating from engagement with offers, meal deals, flash sales and bundle deals, and those where search results were ordered by ascending price. Whilst engagement with offers constituted $23 \%$ of the $>195$ million "adds to basket" events over 2016, with just $1 \%$ were the result of customers actively sorting products by price (Fig. 4). 


\section{Discussion}

The broad aims of this study were to assess the feasibility of using the Morrisons dataset for exploring national level online grocery behaviour; to assess whether there are differences in online and offline grocery consumption; and to examine in detail the features of online grocery that are thought to constrain or change behaviour. This was achieved by considering basket value; basket composition; basket stability and price sensitivity at the national level and in the Morrisons sample. The results and implications of the findings are discussed in sections 5.1-5.4.

\subsection{Is the Morrisons Sample Representative of Online Grocery Shopping at the National Level?}

When considering the composition of the average basket by product category, it was found that the Morrisons sample was significantly different from the LCF 2016 "national average" online group, but that re-weighting the Morrisons sample by region lessened the disparity such that it was no longer statistically significant at the $0.5 \%$ significance level. This was marginally improved by also weighting the sample by internet use by region to correct for the fact that there is currently no dataset that splits regional grocery consumption by online and offline channels.

The identification of a rich dataset which has potential to represent online grocery shopping behaviour at the national level presents exciting opportunities to expand understanding in a sparsely researched field. The extensive body of work to follow this study will not only contribute to the understanding of online grocery consumption, but will also serve as a scoping exercise to help guide research in the field.

\subsection{Are There Differences in Consumption Behaviour Between Online and Offline Grocery Shopping in the UK?}

Average Basket Value The average basket value for the Morrisons sample was found to be $£ 33.56$ p.h.p.w., considerably higher than the natonal average of $£ 20.93$ p.h.p.w., as reported in the LCF 2016. This may indicate that Morrisons shoppers spend more than the national average, or that they shop less frequently, as reported by Robinson et al [35. Furthermore, the national estimate may be an underestimate of average basket size online, since it is based on the proportion of the population who have bought groceries online in the past 12 months, not those who do so on a regular basis.

Basket Composition Comparison of the online and offline LCF 2016 samples indicated strong evidence of difference in the distribution of revenue among product types for online and offline grocery shopping, indicating that online consumption behaviour is different from offline. It was shown that there is some 
evidence that online consumers spend more on fresh products than offline, supporting the findings of Degeratu et al [9], but contrary to popular wisdom that customers are reluctant to shop for fresh produce online [19, 21].

\subsection{Are Online Grocery Shoppers Price Sensitive?}

Interrogation of Morrisons customer basket composition revealed that $23 \%$ of the average basket was populated using price sensitive behaviours, such as engagement with offers and sorting products by price. Whilst there are no comparative offline studies for Morrisons consumers, this finding indicates that the majority of products are added to basket without obvious attention to price and may indicate an overestimation by the retailer of consumer bargain seeking and price comparison behaviours. Furthermore, most "price savvy" adds to basket came from engagement with offers which are prevalent on the site and in search results. As such, the value-seeking behaviour appears to arise primarily from product placement on the part of the retailer. This may suggest an overestimation by the retailer of customer's value-seeking behaviour. This result is concordant with the findings of Urbany et al, who report that in the "offline-only era" retailers tended to 'overestimate the size of the consumer segment that regularly switches stores for price specials' 40. Establishing how Morrisons' online price sensitive behaviour compares to in-store behaviour (and enable generalisation to the UK population) would of course require further empirical investigation.

\subsection{Are Online Grocery Baskets Stable?}

This study also provides initial findings regarding how consumers make product selections by identifying the page on-site from which products were added to basket. It was shown that $39 \%$ of product additions emanate from stable behaviours, such as using previous orders and saved favourites to populate shopping baskets. The vast majority of stable product adds are done so from saved favourites. The majority of all product adds to basket however result from "disrupted" activities, such as site search or engagement with retailer promotions. The high proportion of unstable product adds to basket could indicate that the retailer is overestimating the difficulty in up-selling and infiltrating online baskets.

\section{Conclusions}

This study established that there are differences in consumption behaviour between online and offline grocery shopping in the UK in terms of basket composition by product category. It also provides some evidence that online consumers spend more on fresh products than offline, contrary to popular wisdom that customers are reluctant to shop for fresh produce online [19, 21]. This paper showed that with re-weighting to correct for regional bias, a rich dataset of Morrisons online consumer data has potential to represent national level behaviour. The dataset consists of individual level consumption behaviour and includes features 
such as location, time, device and the names of products purchased. This finding has huge implications for expanding the understanding of online grocery consumption at the national level. To date, the majority of quantitative empirical work has been conducted in non-naturalistic experimental settings and with small sample sizes. In contrast, the identification of this rich dataset facilitates analysis of millions of real-world transactions.

\subsection{Limitations}

The main limitations of this study resided in the lack of offline Morrisons data or high quality online and offline datasets to compare with to conclude whether there have been systematic shifts in consumer behaviour in the online grocery shopping era. Whilst the size of the sample used in this study was vastly bigger than that used by the ONS to estimate national level behaviour, it was still only a small proportion of the wealth of data collected by Morrisons and other retailers.

The assignment of product categories and freshness was not trivial, due to the inconsistent way CIOCOP and LCF surveys report on food categories. Some categories (e.g. fruit and vegetables) were well defined in terms of freshness, whilst others (such as meat and fish) were not divided into fresh and frozen/processed products. Furthermore, complex products containing multiple food groups were difficult to classify and no clear advice for doing so exists in the LCF e-commerce.

\subsection{Future Work}

Future work will identify periodicity in sales revenue; variation in behaviours by location and device use; and how the capacity to edit baskets affects basket composition. The discovery that a high proportion of product adds to basket emanate from unstable sources, such as site search also motivates qualitative investigation. This would involve working with shoppers to ascertain how they engage with online shopping, the reasons they give for their behaviours and further investigating sources of fundamental change in consumption practices. Employing insights from qualitative and quantitative studies will allow theoretical and predictive models of consumption behaviour to be developed.

\section{References}

[1] Bagozzi, R.: The legacy of the technology acceptance model and a proposal for a paradigm shift. Journal of the Association of Information Systems 8(4), 244-254 (2007)

[2] BI Intelligence: Mobile sales drive unexpected uk e-commerce growth. Business Insider UK (2017), http://uk.businessinsider.com/ mobile-sales-drive-unexpected-uk-e-commerce-growth-2017-1

[3] Briesch, R.A., Chintagunta, P.K., Fox, E.J.: How does assortment affect grocery store choice? Journal of Marketing Research 46(2), 176-189 (2009) 
[4] Bulman, J.: Detailed household expenditure by countries and regions, UK: Table A35. Office for National Statistics (2017), https://www.ons.gov.uk/ peoplepopulationandcommunity/...

[5] Business: Ocado profits rise after 'robust trading'. BBC News (2017), http:// www.bbc.co.uk/news/business-38806573

[6] Cohen, J.: Statistical Power Analysis for the Behavioral Sciences. Taylor and Francis, 1 edn. (1988)

[7] Crewe, L., Lowe, M.: Gap on the map? Towards a geography of consumption and identity. Environment and Planning A 27(12), 1877-1898 (1995)

[8] Danaher, P.J., Wilson, I.W., Davis, R.A.: A comparison of online and offline consumer brand loyalty. Marketing Science 22(4), 461-476 (2003)

[9] Degeratu, A.M., Rangaswamy, A., Wu, J.: Consumer choice behavior in online and traditional supermarkets: The effects of brand name, price, and other search attributes. International Journal of Research in Marketing 17(1), 55-78 (2000)

[10] Edwards, J.: Retail sales in great britain - Office for National Statistics (2017), https://www.ons.gov.uk/businessindustryandtrade/retailindustry/...

[11] Employee, M.: Interview with Morrisons (technical) employee (2016)

[12] Evanschitzky, H., Iyer, G., Hesse, J., Ahlert, D.: E-satisfaction: a re-examination. Journal of Retailing 80(3), 239-247 (2004)

[13] Hand, C., Dall'Olmo Riley, F., Harris, P., Singh, J., Rettie, R.: Online grocery shopping: the influence of situational factors. European Journal of Marketing 43(9/10), 1205-1219 (2009)

[14] Hansen, T.: Consumer adoption of online grocery buying: a discriminant analysis. International Journal of Retail Distribution Management 33(2), 101-121 (2005)

[15] Huang, Y., Oppewal, H.: Why consumers hesitate to shop online. International Journal of Retail Distribution Management 34(4/5), 334-353 (2006)

[16] IGD.com: Larger stores rally as uk food and grocery forecast to grow by $10 \%$ over next five years (2016), http://www.igd.com/About-us/Media/ IGD-news-and-press-releases/...

[17] Julka, H.: Tech in Asia - connecting Asia's startup ecosystem (2016), https: //www.techinasia.com/...

[18] Keifer, S.: Why the internet is forcing retailers to rethink their supply chains. Computer Weekly p. 15 (2013), http://www.computerweekly.com/opinion/ Why-the-internet-is-forcing-retailers-to-rethink-their-supply-chains

[19] Kestenbaum, R.: Why online grocers are so unsuccessful and what amazon is doing about it. Forbes.com Retail (2017), https://www.forbes.com/sites/ richardkestenbaum/2017/01/16/...

[20] Maity, M., Dass, M.: Consumer decision-making across modern and traditional channels: E-commerce, m-commerce, in-store. Decision Support Systems 61, 34-46 (2014)

[21] Marino, J.: The online grocery business faces a unique challenge. Business Insider UK (2015), http://uk.businessinsider.com/ grocery-delivery-challenges-2015-3?r=US\&IR=T

[22] Marr, B.: Big data and shopping: How analytics is changing retail. LinkedIn (2015), https://www.linkedin.com/pulse/ big-data-shopping-how-analytics-changing-retail-bernard-marr

[23] Michaud Trevinal, A., Stenger, T.: Toward a conceptualization of the online shopping experience. Journal of Retailing and Consumer Services 21(3), 314-326 (2014)

[24] Miller, D.: A Theory of Shopping. Polity Press, 1 edn. (1998) 
[25] Morrisons.com: Groceries.morrisons.com (2017), https://groceries. morrisons.com/webshop/startWebshop.do

[26] Murphy, A.J.: (Re)solving space and time: Fulfilment issues in online grocery retailing. Environment and Planning A 35(7), 1173-1200 (2003)

[27] Neville, S.: Tesco: Who says it's hard to make home delivery profits? Independent (2014), http://www .independent.co.uk/news/business/news/ tesco-who-says-its-hard-to-make-home-delivery-profits-9153185.html

[28] Newman, D.: Reimagining the holiday experience with big data. IBM THINK Marketing (2016), https://www.ibm.com/think/marketing/ reimagining-the-holiday-experience-with-big-data/

[29] Office for National Statistics: Retail sales, march 2012 (2012), http:// webarchive.nationalarchives.gov.uk/20160105160709/...

[30] Office for National Statistics: Internet users in the UK: 2016 (2016), https: //www.ons.gov.uk/businessindustryandtrade/itandinternetindustry/ bulletins/internetusers/2016

[31] Office for National Statistics: Mid-2015 (2017), https://www.ons . gov.uk/peoplepopulationandcommunity/populationandmigration/ populationestimates/...

[32] Rafiq, M., Fulford, H.: Loyalty transfer from offline to online stores in the uk grocery industry. International Journal of Retail Distribution Management 33(6), 444-460 (2005)

[33] Reichheld, F.F., Sasser Jr., W.E.: Zero defections: Quality comes to services. Harvard Business Review 68(5), 105-111 (2000)

[34] Ritzer, G.: The McDonaldization of society 6. Sage, 1 edn. (2011)

[35] Robinson, H., Dall'Olmo Riley, F., Rettie, R., Rolls-Willson, G.: The role of situational variables in online grocery shopping in the uk. The Marketing Review 7(1), 89-106 (2007)

[36] Rohm, A.J., Swaminathan, V.: A typology of online shoppers based on shopping motivations. Journal of Business Research 57(7), 748-757 (2004)

[37] Szymanski, D.M., Hise, R.T.: E-satisfaction: an initial examination. Journal of Retailing 76(3), 309-322 (2000)

[38] Thachenkary, C., Chatterjee, S., Katz, J.: Successful product characteristics for electronic commerce: a taxonomy of transaction types. 1997 Fourth International Workshop on Community Networking Processing (1997)

[39] United Nations Statistics Division: United nations statistics division - classifications registry (2017), https://unstats .un.org/unsd/cr/registry/regcst . asp? $\mathrm{Cl}=5$

[40] Urbany, J.E., Dickson, P.R., Sawyer, A.G.: Insights into cross- and within-store price search: retailer estimates vs. consumer self-reports. Journal of Retailing 76(2), 243-258 (2000)

[41] Wajcman, J.: Pressed for time: the acceleration of life in digital capitalism. University of Chicago Press, 1 edn. (2015)

[42] Wang, R.J.H., Malthouse, E.C., Krishnamurthi, L.: On the go: How mobile shopping affects customer purchase behavior. Journal of Retailing 91(2), 217-234 (2015)

[43] Worldpanel, K.: Global e-commerce grocery market has grown $15 \%$ to $48 \mathrm{bn}$. Kantar Worldpanel News (2016), https://www.kantarworldpanel.com/global/ News/Global-e-commerce-grocery-market-has-grown-15-to-48bn 